\title{
Risk Management of Online Travel Supply Chain
}

Jin Wang ${ }^{1, a}$ and Min Zhao ${ }^{2, \text { b, * }}$

${ }^{1}$ Management School, Shanghai University, Shanghai, 200444, China

${ }^{2}$ Sydney Institute of Language and Commerce, Shanghai University, Shanghai, 201800, China

awangjin_94@163.com, bhaomin1226@163.com

\section{Keywords: Online travel; Supply chain; AHP; FCE}

\begin{abstract}
Online tourism has become a new format because of its cross-industry and crossboundary which makes the online travel supply chain more risky than the traditional ones. This paper established a complete online travel supply chain risk assessment system to realize the assessment. By innovatively introducing fuzzy mathematics into the analytic hierarchy process, the AHP-FCE method was presented for evaluating the risk probability and risk loss. The weighting coefficients of the indexes were calculated using the analytic hierarchy process (AHP) while the fuzzy comprehensive evaluation (FCE) was used to realize the multilayer comprehensive evaluation. Using the above evaluation system would help to better understand the risks of online tourism supply chain, prevent the occurrence of online tourism supply chain risk, and reduce losses.
\end{abstract}

\section{Introduction}

In the "Internet +" era of tide, the tourism industry ushers in a new development opportunity. Online travel as the organic combination of tourism and Internet, has attracted more and more attention. According to the "2012 China Internet users travel booking behavior survey report", as of June 2012, China's users of travel booking got into 42.58 million. The survey by leading online market research company iResearch shows that in 2015, China's online travel market turnover reached 6.54 trillion RMB. It is clear from these data that China's tourism e-commerce development prospects are very broad.

In recent years, the online tourism industry becomes booming, domestic and foreign research about online travel website is also more and more. Burgess ${ }^{[1]}$ conducted an empirical analysis of 12,000 online travel consumers in Australia. The study found that consumers use tourism information through travel product sellers, travel industry experts and other travel consumers to decide whether to buy tourism products. Tsai C.H. ${ }^{[2]}$ explored the impact of various natural disasters on tourism risks, and combined the expert to allocate the weight of natural disaster risk index assessment, and established a rapid risk assessment model suitable for the tourism industry to help the tourism asset owners to do the worst. Charlels ${ }^{[3]}$ described the importance of policies solving the risks and safety associated with tourism. Xinyan Zhang ${ }^{[4]}$ examined the characteristics of tourism products, identified and explored the core issues and concepts of tourism supply chain (TSC) and tourism supply chain management (TSCM). Xiaoye $\mathrm{Ji}^{[5]}$ took the four well-known travel websites as examples, and use the AHP and the interval fuzzy TOPSIS to evaluate the consumer trust. Please remember that all the papers must be in English and without orthographic errors.

It can be seen that the research on online tourism supply chain is limited to the qualitative and quantitative assessment of online tourism, while the study of tourism risk is related to a certain aspect, and there is little research combining risk with the online tourism supply chain. However, the online tourism supply chain as a whole to achieve stable and effective operation, it needs to be a risk study as a whole. By referring to the research of supply chain risk, this paper combined with the feature of online travel industry to analyze online travel industry supply chain risk. 


\section{Online Tourism Supply Chain Risk Identification}

Online tourism supply chain risk identification is the first step in supply chain risk management. The risk of the supply chain has mainly three aspects: internal risk, inter-firm risk and system external risk. However, the online tourism supply chain is different from the general supply chain, because it has a large user group and integrates a lot of information within the chain of other enterprises, online travel sites in the supply chain occupy the core position. The online travel website, through the interaction information and integration with travel agencies, hotels and transportation, replaces the traditional travel agency directly to tourists to provide fast, comprehensive travel information inquiries and ticketing booking. Therefore, this study occupied online travel site as the center, and launched respectively upstream and downstream along the supply chain. It would ensure the focus of the study, but also considered the supply chain members of the cooperative relationship.

Based on the existing research ${ }^{[6]}$, this paper has 14 influencing factors, classified as 4 categories, as shown in Table 1.

Table 1 online tourism supply chain risk

\begin{tabular}{|c|c|c|}
\hline First level indicatiors & Second level indicatiors & Explanation \\
\hline \multirow{4}{*}{$\begin{array}{l}\text { Strategy and } \\
\text { organizational culture } \\
\text { factors } M_{l}\end{array}$} & Strategic plan risk $M_{11}$ & Strategic planning is not accurate \\
\hline & Corporate culture risk $M_{12}$ & Corporate culture values are inconsistent \\
\hline & Strategic target risk $M_{13}$ & $\begin{array}{l}\text { Supply chain members' strategic objectives } \\
\text { are inconsistent }\end{array}$ \\
\hline & Supply chainvertical risk $M_{14}$ & Supply chain vertical integration is not high \\
\hline \multirow[t]{3}{*}{ Cooperation factors $M_{2}$} & Moral hazard $M_{21}$ & $\begin{array}{l}\text { hidden information which is not conducive } \\
\text { to their own in Cooperation }\end{array}$ \\
\hline & Distribution of benefits risk $M_{22}$ & conflict of interest among partners \\
\hline & Information disclosure risk $M_{23}$ & Partner discloses information \\
\hline \multirow{4}{*}{$\begin{array}{l}\text { External environmental } \\
\text { factors } M_{3}\end{array}$} & Political risk $M \quad 31$ & Political intervention, social order, war \\
\hline & Economic risk $M_{32}$ & $\begin{array}{l}\text { Interest rate, exchange rate, stock market, } \\
\text { financial crisis }\end{array}$ \\
\hline & Natural risk $M_{33}$ & Natural disasters, climate \\
\hline & Legal risk $M_{34}$ & $\begin{array}{l}\text { The adjustment of laws and regulations, the } \\
\text { uncertainty of revision }\end{array}$ \\
\hline \multirow[t]{3}{*}{ Demand risk factor $M_{4}$} & Customer demand risk $M_{41}$ & $\begin{array}{l}\text { The customer's needs are changing fast and } \\
\text { big }\end{array}$ \\
\hline & Customer changes risk $M_{42}$ & $\begin{array}{l}\text { Customer changes are too large or key } \\
\text { customers loss }\end{array}$ \\
\hline & $\begin{array}{l}\text { Customer relationship } \\
\text { management } M_{43}\end{array}$ & $\begin{array}{l}\text { Insufficient customer relationship } \\
\text { management }\end{array}$ \\
\hline
\end{tabular}

\section{Model Establishment}

Because risk measurement is difficult to quantify, this paper mainly uses AHP and FCE to evaluate the risk of online tourism supply chain. Using AHP method to determine the weight of each layer index, and FCE method to construct evaluation matrix and establish risk assessment model of online tourism supply chain.

\section{Weights Building}

By the expert survey results and the AHP method, the weight set $\omega_{i}$ of the online tourism supply chain risk secondary index set $M_{i}$ is

$$
\begin{array}{ll}
\omega_{1}=(0.4821,0.1170,0.2178,0.1831)^{T} & \omega_{2}=(0.1220,0.2297,0.6483)^{T} \\
\omega_{3}=(0.5530,0.1312,0.2704,0.0454)^{T} & \omega_{4}=(0.5297,0.3325,0.1396)^{T}
\end{array}
$$




\section{The weight set $\omega$ of the first-level index set $M$ is}

$$
\omega=(0.2797,0.4704,0.1142,0.1357)^{T}
$$

\section{Membership Matrix Creating}

For the online tourism supply chain risk analysis, Index factors are often difficult to quantify. So this paper used expert investigation method to obtain their membership. Strategy and organizational culture factor indicator set $M_{1}=\left(M_{11}, M_{12}, M_{13}, M_{14}\right)$ risk probability survey results are shown in Table 2.

Table 2 Strategy and organizational culture factor risk probability expert questionnaire

\begin{tabular}{cccccc}
\hline Factor & Very low & Low & Medium & High & Very high \\
\hline$M_{11}$ & 0.04 & 0.06 & 0.37 & 0.46 & 0.07 \\
$M_{12}$ & 0.02 & 0.09 & 0.31 & 0.47 & 0.11 \\
$M_{13}$ & 0.04 & 0.11 & 0.15 & 0.22 & 0.48 \\
$M_{14}$ & 0.07 & 0.08 & 0.10 & 0.40 & 0.35 \\
\hline
\end{tabular}

By the strategic and organizational cultural factors risk probability results, risk probability membership matrix $R_{1}$ of strategic and organizational culture factor $M_{1}$ and the other index membership matrix $\mathrm{R}_{i}$ are shown as below.

$$
\begin{aligned}
& R_{1}=\left[\begin{array}{ccccc}
0.04 & 0.06 & 0.37 & 0.46 & 0.07 \\
0.02 & 0.09 & 0.31 & 0.47 & 0.11 \\
0.04 & 0.11 & 0.15 & 0.22 & 0.48 \\
0.07 & 0.08 & 0.10 & 0.40 & 0.35
\end{array}\right] \quad R_{2}=\left[\begin{array}{ccccc}
0.01 & 0.12 & 0.23 & 0.31 & 0.33 \\
0.02 & 0.14 & 0.19 & 0.27 & 0.38 \\
0.15 & 0.12 & 0.23 & 0.32 & 0.18
\end{array}\right] \\
& R_{3}=\left[\begin{array}{lllll}
0.10 & 0.24 & 0.45 & 0.20 & 0.01 \\
0.09 & 0.22 & 0.40 & 0.28 & 0.01 \\
0.11 & 0.35 & 0.30 & 0.24 & 0.00 \\
0.13 & 0.30 & 0.35 & 0.22 & 0.00
\end{array}\right] \quad R_{4}=\left[\begin{array}{lllll}
0.08 & 0.12 & 0.34 & 0.44 & 0.02 \\
0.06 & 0.11 & 0.40 & 0.38 & 0.05 \\
0.05 & 0.07 & 0.37 & 0.43 & 0.08
\end{array}\right]
\end{aligned}
$$

\section{Multi-Level Comprehensive Evaluation}

Take the risk probability estimate as an example. According to the obtained $\omega_{i}$ and $R_{i}$, the secondary index evaluation set $B_{i}$ are shown as below.

$$
\begin{array}{ll}
B_{1}=(0.0570,0.0896,0.3014,0.3746,0.1774) & B_{2}=(0.1402,0.1309,0.2150,0.2992,0.2147) \\
B_{3}=(0.1018,0.2503,0.4165,0.2221,0.0093) & B_{4}=(0.0755,0.1132,0.3207,0.4151,0.0755)
\end{array}
$$

So the first-level index evaluation set $B$ is shown as below.

$$
B=(0.2797,0.4704,0.1142,0.1357) \cdot\left[\begin{array}{l}
B_{1} \\
B_{2} \\
\vdots \\
B_{m}
\end{array}\right]=(0.1038,0.1306,0.2765,0.3272,0.1619)
$$

Online travel supply chain risk probability score $D$ is shown as below.

$$
D=B \cdot(0.1,0.3,0.5,0.7,0.9)^{T}=0.5626
$$

In the same way, the risk loss score is 0.6259 .

Compared with the risk probability and risk loss standard, the risk probability of the online travel website belongs to the middle, the risk loss is high, indicating that the site have to pay high attention to this problem, and immediately take countermeasures to strengthen the risk prevention and control. 


\section{Risk Control}

In the supply chain risk management, guarding against risk is the most important core work. The risk of the supply chain should strengthen the real-time monitoring of the weak links in the supply chain and developing normative day-to-day controls to reduce the risk. According to the above results, we can see that in the online tourism supply chain risk, the strategic and organizational cultural factors and cooperation factors account for a large proportion, so this paper focuses on the characteristics of the online tourism supply chain, put forward the following preventive measures:

(1) Preventing strategy and organizing cultural risks. Any transaction of online travel services is comprised of the three basic "flow", information flow, business flow and capital flow. Any tourism website can not be prepared for everything. Therefore, in the strategic alliance strategy, the online travel site could optimize the online travel service value chain, continue to strengthen with airlines, hotels, attractions and other upstream suppliers cooperation, also includes the online travel vertical search engine, review sites, offline travel agencies and other peer-to-peer alliance, and banks, businesses, large integrated e-commerce sites and other industries mixed alliance.

(2) Preventing cooperation risks. They could use modern information technology to strengthen information sharing, establish internal information systems, so that make rapid response to information with exterior enterprise, establish cross-enterprise information systems to achieve information sharing and effective exchange. At the same time, design cooperation contract, in which clear the rights and obligations of the parties. It can be regarded as the basis for accountability of risk, which can effectively prevent moral hazard.

(3) Preventing external environmental risks. Natural environmental risks is resistless, so it would take precautionary measures in advance to minimize losses, such as using insurance markets to defend, mitigate and mitigate risks. Social risk is different with natural risk, avoidance measures can be used to reduce losses.

(4) Preventing demand risk. With the problem in hand, the online travel site could use a variety of promotional tools to complement and coordinate. The online travel websites should pay attention to business and customer communication. In addition to published in the newspapers and magazines unilateral advertising, they can use huge customer information to gather intelligence, or using network marketing tools monitoring market trends, collecting user needs and feedback, analyzing user characteristics, improving service or providing better after-sales service.

\section{Conclusions}

Although the entire supply chain is a community of interests, the enterprises in supply chain business are independent business entities, in addition to their respective business strategy, management system, and corporate culture are different, even exist multiple goals conflict with each other. These greatly increased the complexity and uncertainty of the supply chain, and lead to a lot of risk factors in the supply chain. Online tourism is basking in a great boom, how to implement effective risk management to improve the efficiency of the entire supply chain and enhance the competitiveness have become urgent needs. Based on the research of risk management theory in supply chain management environment and the development of online tourism in China, this paper put forward a complete set of online tourism supply chain risk management method. The results are as follows:

(1) This paper established a complete online tourism supply chain risk identification process and systematically analyzed the possible risks and influencing factors of online tourism supply chain, and puts forward the index system of online tourism supply chain risk assessment.

(2) Based on AHP and FCE, the risk estimation process of online tourism supply chain was established by using AHP-FCE. The weight of the index factor is obtained by AHP, identified risk and determined the probability and the loss of risk by FCE.

(3) Through the above research, a set of online tourism supply chain risk assessment system was established to analyze the potential risks of online tourism supply chain, prevent and control these risks. 
This paper mainly studied the risk management of online tourism supply chain, and the relevant risk measurement, control and prevention still need further study and discussion.

\section{References}

[1] S. Burgess, C. Sellitto, C. Cox, J. Buultjens, Trust per-ceptions of online travel information by different content creators: some social and legal implications. Information Systems Frontiers, 13(2011) 221-235.

[2] C.H. Tsai, C.W. Chen, The establishment of a rapid natural disaster risk assessment model for the tourism industry. Tourism Management, 32(2011)158-171.

[3] Brossman. Charles, 4-Travel risk policies, compliance, and supplier safety. Building a Travel Risk Management Program, (2016)81-100.

[4] Xinyan Zhang, Haiyan Song, George Q. Huang. Tourism supply chain management: A new research agenda. Tourism Management, (2009)345-358.

[5] Xiaoye Ji, Youyuan Peng, Li Yang. Fuzzy evaluation of consumer trust in the perspective of online tourism service supply chain. Tourism Economy, 12(2015)140-146.

[6] Lu Zhang, Jin Qin. Online travel service supply chain risk analysis. Chinese Journal of Management Science, 20(2012)580-585. 